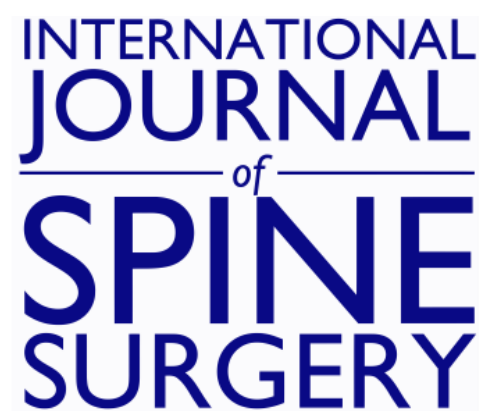

\title{
A Case Report of Complete Dislocation of Atlantoaxial Joint due to a Traumatic and Pathological Axial Lesion
}

Xinwei Yuan, Lun Wan, Jiang Hu and Wei Zhang

Int J Spine Surg 2021, 14 (s4) S5-S9

doi: https://doi.org/10.14444/7157

http://ijssurgery.com/content/14/s4/S5

This information is current as of April 26, 2023.

Email Alerts Receive free email-alerts when new articles cite this article. Sign up at:

http://ijssurgery.com/alerts

The International Journal of Spine Surgery

2397 Waterbury Circle, Suite 1,

Aurora, IL 60504, Phone: +1-630-375-1432 


\title{
A Case Report of Complete Dislocation of Atlantoaxial Joint due to a Traumatic and Pathological Axial Lesion
}

\author{
XINWEI YUAN, MD, LUN WAN, BD, JIANG HU, MD, WEI ZHANG, PhD \\ Department of Orthopedics, Sichuan Academy of Medical Sciences and Sichuan Provincial People's Hospital, Chengdu, Sichuan, P.R. China
}

\begin{abstract}
Background: Atlantoaxial dislocation usually results in sudden death. The patient had never found any axial lesion before, and the atlantoaxial joint dislocation was caused by rotation of the neck due to discomfort of the neck. The patient was given surgical treatment after the rescue of respiratory and cardiac arrest during transportation, which was extremely rare and rarely reported.

Methods: A 62-year-old male patient presented with limited cervical mobility after a violent rotation of the neck due to neck discomfort. X-ray and computed tomography (CT) scan suggested atlantoaxial dislocation. Sudden respiratory and cardiac arrest during transportation was immediately followed by continuous cranial traction and successful occipital and neck fusion operation.

Results: After the successful rescue of endotracheal intubation, the patient was given continuous cranial traction. After the completion of CT scan, the patient was given occipital neck fusion, and 6 days after the surgery, the patient wore the skull-neck-thorax brace and walked freely.

Conclusion: Continuous cranial traction and posterior occipitocervical fusion are effective methods for treating axial pathological fracture with atlantoaxial dislocation.
\end{abstract}

Level of Evidence: 5.

Cervical Spine

Keywords: atlantoaxial dislocation, occipitocervical fusion, cranial traction

\section{INTRODUCTION}

Rheumatic diseases, trauma, and tumor are the common causes of atlantoaxial dislocation. ${ }^{1}$ Occipitocervical fusion is generally applicable to upper cervical fracture and dislocation where atlantoaxial fusion is not possible. ${ }^{2}$ It is also one of the effective methods to correct upper cervical instability, and effective bone grafting is also a prerequisite for occipitocervical fusion. ${ }^{3}$

\section{CASE REPORT}

The patient was a 62-year-old male patient who felt neck discomfort 3 days before admission. After being violently attacked by others, he immediately felt neck pain and discomfort with limited movement. Cervical spine computed tomography (CT) scan was performed immediately in the local hospital, indicating that cervical 2 vertebral bone destruction was diagnosed as axial vertebra lesion in the local hospital, and the local hospital suggested to transfer the patient to the hospital for treatment. The family members led the patient to the outpatient clinic of our hospital from a distance of approximately $300 \mathrm{~km}$. In the outpatient examination, the neck was askew to the front and bottom of the right, and the muscle strength of the limbs was normal. American Spinal Cord Injury Association was rated as grade E. Xray (Figure 1) and CT (Figure 2) examinations of the cervical spine were performed immediately, suggesting pathological axial fracture with atlantoaxial dislocation. The patient was admitted to the Emergency Intensive Care Unit immediately. In the process of transfer, the patient suffered sudden breathing and cardiac arrest, and was immediately given endotracheal intubation and ventilator-assisted treatment. The patient regained spontaneous heart rate and respiration, and sustained cranial traction was given after the condition was stable. Cervical spine CT scan review (Figure 3) indicated good atlantoaxial joint 

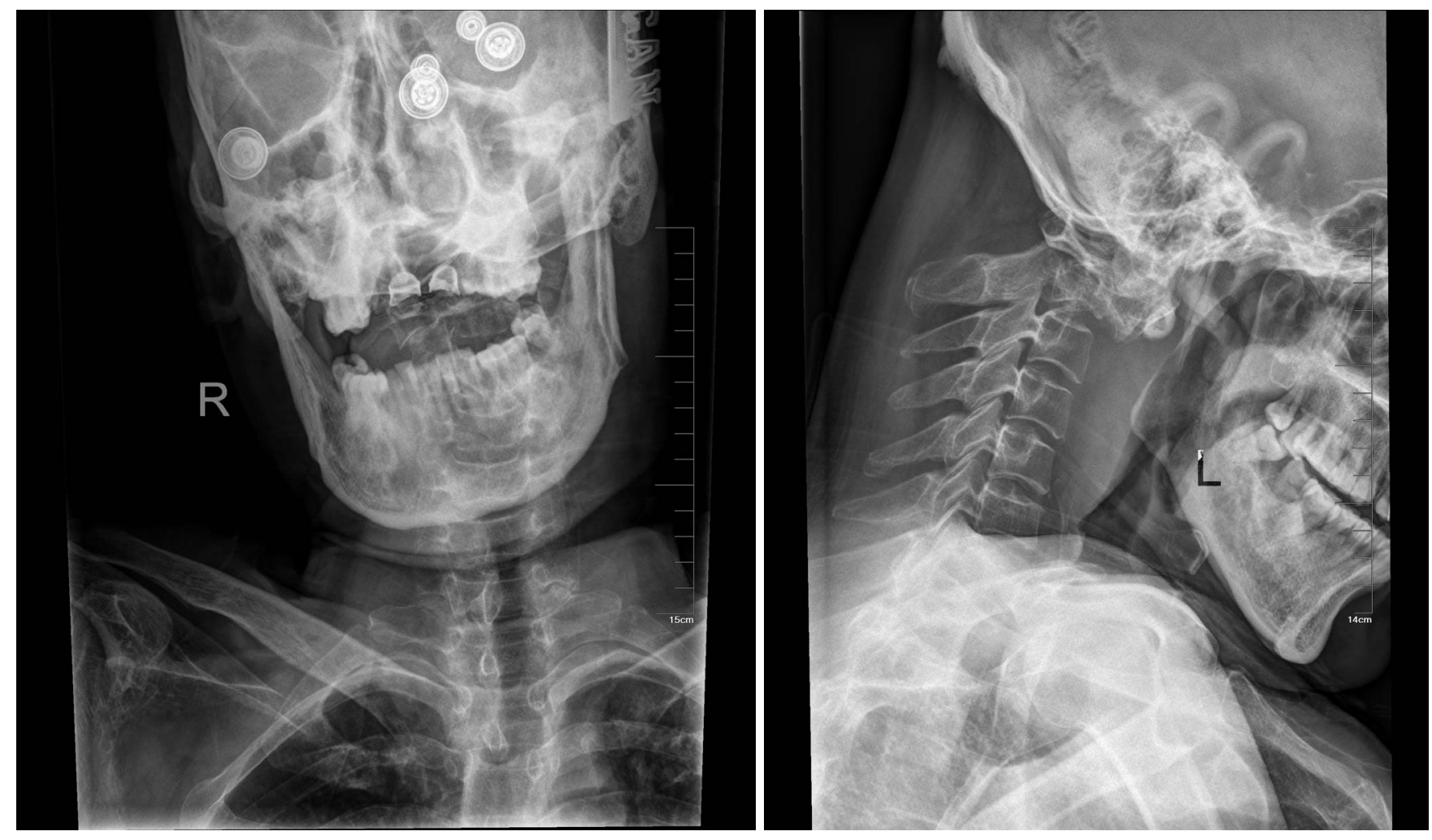

Figure 1. Preoperative anteroposterior x-ray (left) and preoperative lateral x-ray (right). Overlap of the atlas posterior arch with the axial odontoid can be seen on lateral radiographs.

reduction. After the completion of the examination, the patient was given occipitocervical fusion under general anesthesia. Axial vertebral body damage was found during the operation, and local biopsy was taken for examination. Postoperative disease examination suggested that there was a little degenerated bone tissue and necrotic components. Postoperative X-ray showed good internal fixation position (Figure 4).

\section{DISCUSSION}

Atlantoaxial dislocation can be divided into partial and complete dislocation. Most patients with complete dislocation die on the spot, although it is rare for the patient to travel to many places without death. The reason may be that dislocation accompanied by local bone destruction leads to slight expansion of spinal canal volume, and no respiratory or cardiac arrest occurs in the mobile position. Tuberculosis of the cervical spine is more rarely reported, accounting for $0.3 \%-1 \%$ of systemic tuberculosis. ${ }^{4,5}$ Cervical tuberculosis may not be detected at the early stage. Because the patient has no clinical symptoms, the present onset is neck discomfort and posttraumatic atlantoaxial dislocation. Moreover, the role of polymerase chain reaction in the diagnosis of bone tuberculosis is not clear ${ }^{6,7}$ because it can be rapidly excluded but cannot be diagnosed, ${ }^{8}$ as shown in this case.

Atlantoaxial tuberculosis often leads to bone destruction of atlantooccipital joint, and local ligament relaxation leads to atlanto-occipital joint instability, so it is particularly important to clear the lesion and reconstruct the stability of upper cervical vertebra. ${ }^{9}$ Although anterior surgery can achieve the purpose of clearing lesions and decompression of spinal canal, anterior surgery is difficult to reconstruct the stability of atlas and occipital region, and posterior surgery can achieve the purpose of bone grafting and fusion internal fixation, ${ }^{10}$ but posterior surgery alone is difficult to completely remove lesions, so the selection of surgical methods is particularly important. ${ }^{11}$ In this case, no local pharyngeal wall abscess was 

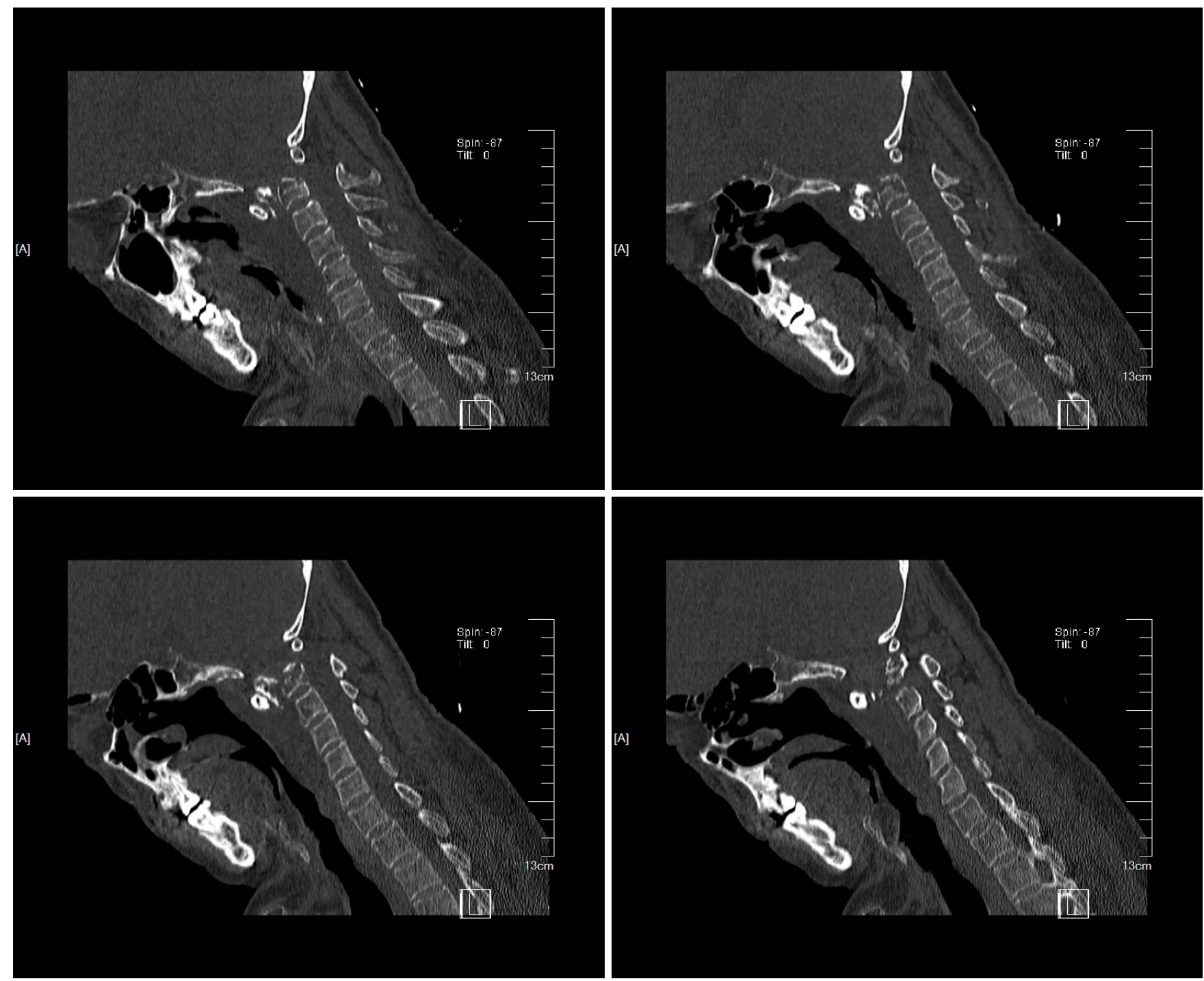

Figure 2. Preoperative computed tomography scan sagittal view showed axial odontoid fracture. The fracture end is located in front of the axial body.

found to form before surgery, so posterior surgery was performed directly after skull traction. However, for other patients with tuberculosis with abscess formation, anterior decompression and posterior fixation and fusion surgery were required, so as to better restore the stability of upper cervical vertebra.

The choice of autologous bone graft or allograft fusion in occipitocervical fusion has always been controversial. Godzik et $\mathrm{al}^{12}$ believed that the success rate of allograft fusion was relatively high, and the occurrence of complications related to body bone was avoided. The thickest part of the occipital region is mostly located in the external carinal process. ${ }^{13}$ It is still controversial to fix the occipitocervical fusion vertebra to $\mathrm{C} 2$ or $\mathrm{C} 3$. Pan et $\mathrm{al}^{14}$ found no statistical difference in the rate of fixed $\mathrm{C} 2$ or $\mathrm{C} 3$ fusion, but there were more complications in the treatment group than in $\mathrm{C} 2$. In this case, due to the obvious axial vertebra destruction, we adopted cervical 3 in the operation, and the postoperative effect was good.

\section{CONCLUSIONS}

Continuous cranial traction and posterior occipitocervical fusion are effective methods for treating axial pathological fracture with atlantoaxial dislocation. 

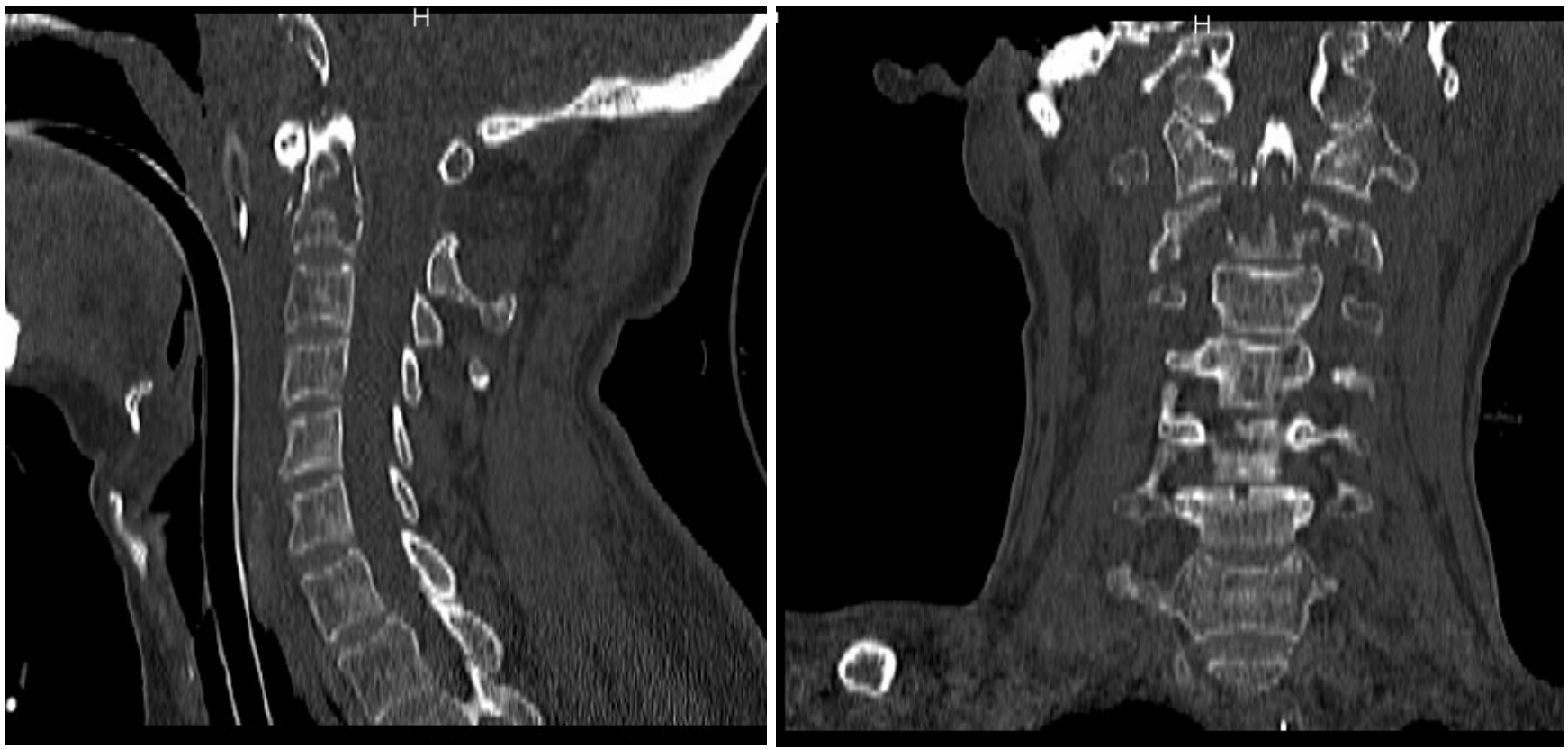

Figure 3. Complete reduction was seen in the sagittal and coronal positions after cranial traction.
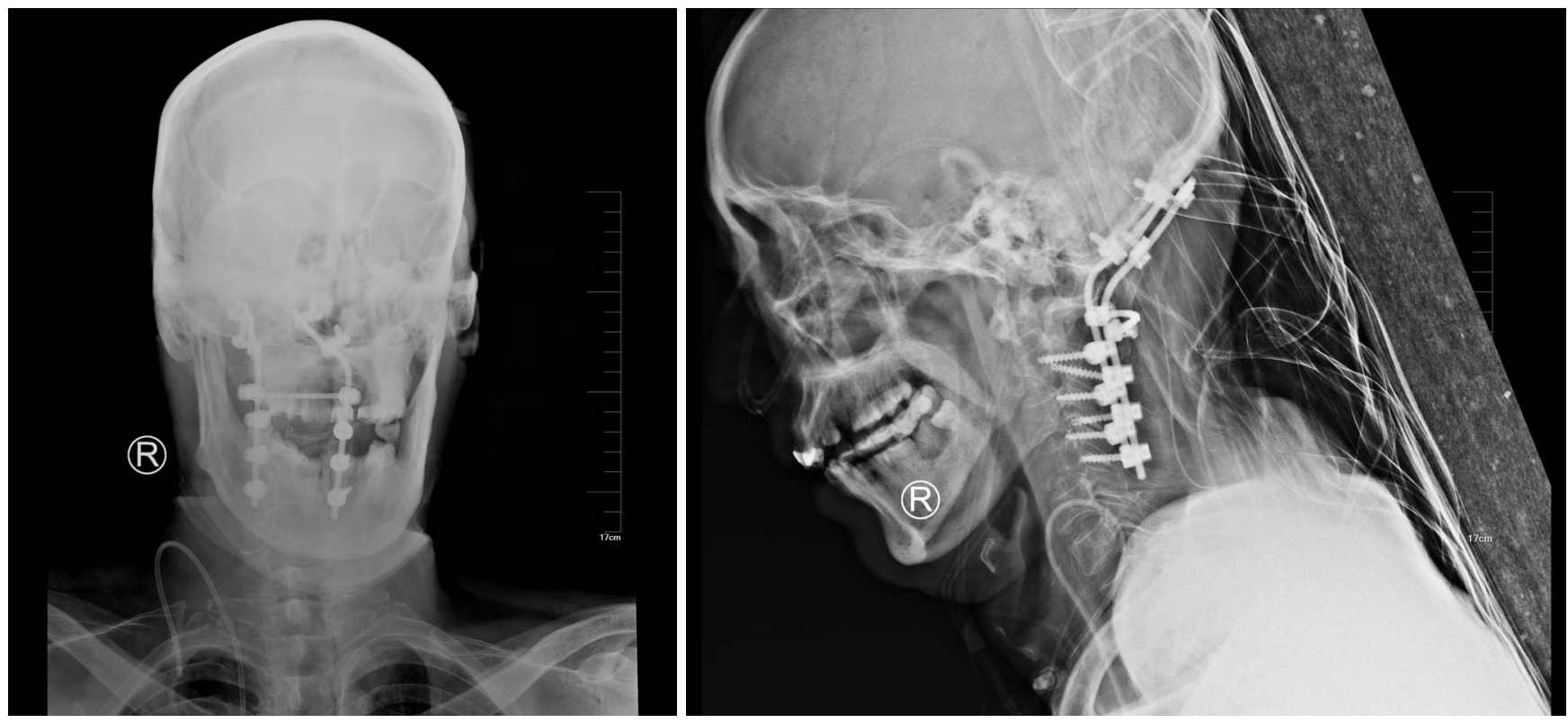

Figure 4. Postoperation anteroposterior $\mathrm{x}$-ray (left) and postoperation lateral $\mathrm{x}$-ray (right).

\section{REFERENCES}

1. Barbagallo GM, Certo F, Visocchi M, Palmucci S, Sciacca $\mathrm{G}$, Albanese V. Disappearance of degenerative, non-inflammatory, retro-odontoid pseudotumor following posterior $\mathrm{C} 1-\mathrm{C} 2$ fixation: case series and review of the literature. Eur Spine J. 2013;22(6):S879-S888. doi:10.1007/s00586-013-3004-1

2. Cacciola F, Boszczyk B, Perrini P. Realignment of basilar invagination by $\mathrm{C} 1-\mathrm{C} 2$ joint distraction: a modified approach to a paradigm shift. Acta Neurochir Suppl. 2019;125:273-277. doi:10.1007/978-3-319-62515-7_39
3. Hussain I, Schwartz TH, Greenfield JP. endoscopic endonasal approach to the upper cervical spine for decompression of the cervicomedullary junction following occipitocervical fusion. Clin Spine Surg. 2018;31(7):285-292. doi:10.1097/BSD. 0000000000000620

4. Edwards RJ, David KM, Crockard HA. Management of tuberculomas of the craniovertebral junction. $\mathrm{Br} J$ Neurosurg. 2000;14(1):19-22. doi:10.1080/02688690042852

5. Teegala R, Kumar P, Kale SS, et al. Craniovertebral junction tuberculosis: a new comprehensive therapeutic strate- 
gy. Neurosurgery. 2008;63(5):946-955. doi:10.1227/01.NEU. $0000327696.77814 .1 \mathrm{E}$

6. Raviglione M, Sulis G. Tuberculosis 2015: burden, challenges and strategy for control and elimination. Infect Dis Rep. 2016;8(2):6570. doi:10.4081/idr.2016.6570

7. Christoforidou A, Metallidis S, Kollaras P, et al. Tuberculous retropharyngeal abscess as a cause of oropharyngeal dysphagia. Am J Otolaryngol. 2012;33(2):272-274. doi:10. 1016/j.amjoto.2011.06.006

8. Olaru I, Heyckendorf J, Grossmann S, et al. Time to culture positivity and sputum smear microscopy during tuberculosis therapy. PLoS One. 2014;9(8):e106075. doi:10. 1371/journal.pone.0106075

9. Rachdi I, Fekih Y, Daoud F. Cervical Pott's disease revealed by retropharyngeal abscess. Presse Med. 2018;47(10):918-921. doi:10.1016/j.lpm.2018.08.010

10. Tan LA, Riew KD, Traynelis VC. Cervical spine deformity_Part 3: posterior techniques, clinical outcome, and complications. Neurosurgery. 2017;81(6):893-898. doi:10.1093/ neuros/nyx477

11. Tanaka S, Aoki M, Nakanishi T, et al. Retrospective case series analysing the clinical data and treatment options of patients with a tubercular abscess of the chest wall. Interact Cardiovasc Thorac Surg. 2012;14(3):249-252. doi:10.1093/icvts/ivr113

12. Godzik J, Ravindra VM, Ray WZ, et al. Comparison of structural allograft and traditional autograft technique in occipitocervical fusion: radiological and clinical outcomes from a single institution. J Neurosurg Spine. 2015;23(2):144-152. doi:10.3171/2014.12.SPINE14535
13. Wang YL, Xu HM, Wang XY, et al. A computed tomographic morphometric study of the pediatric occipital bone thickness: Implications for pediatric occipitocervical fusion. Spine. 2015;40(20):1564-1571. doi:10.1097/BRS.0000000000001091

14. Pan J, Huang D, Hao D, et al. Occipitocervical fusion: fix to C2 or C3? Clin Neurol Neurosurg. 2014;127:134-139. doi:10.1016/j.clineuro.2014.10.013

Disclosures and COI: The authors received no funding for this study and report no conflicts of interest.

Corresponding Author: Xinwei Yuan, Department of Orthopedics, Sichuan Academy of Medical Sciences and Sichuan Provincial People's Hospital, No. 32 Yihuan Rd, Chengdu, Sichuan 610072, P.R. China. Phone: (028) 87394411; Email: agua1987@163.com.

Published 11 February 2021

This manuscript is generously published free of charge by ISASS, the International Society for the Advancement of Spine Surgery. Copyright @ 2020 ISASS. To see more or order reprints or permissions, see http://ijssurgery.com. 